\title{
Different Versions of the Monty Hall Problem
}

\author{
Mazen Alrahili \\ Faculty Member in the Department of Physics at \\ Taibah University,Al- Medina, \\ Saudi Arabia. \\ Department of Physics at Clark Atlanta University, \\ Atlanta, GA, USA.
}

\begin{abstract}
The Monty Hall problem is a conditional probability example in which one of three doors has a big prize and other two doors conceive worthlessly. The game features are a rational decision between stay or switch given the constraints of the game. This paper aims to explain the different versions of the Monty Hall Problem in a many way to approve and solve the Monty Hall problem.
\end{abstract}

\section{General Terms \\ Monty Hall Problem.}

\section{Keywords}

Keywords are your own designated keywords which can be used for easy location of the manuscript using any search engines.

\section{INTRODUCTION}

This paper will provide a quantum model of the Monty Hall problem. Monty Hall was the celebrated host of a TV amusement demonstrate "Let's Make a Deal," one of the bestknown game shows [10]. As a game appear, changed designs of the standard program looked all through the accompanying 40 years, with the following attempts achieving little unmistakable quality diverged from the activities communicate in the 1970s. In the distinctive adaptations of the amusement demonstrate that showed up unpredictably on TV from 1963 until 2003, different answers for manage the three entryways were introduced, with expansions, for example, joining the fourth entryways in 1984. In light of the amusement appear, there is outstanding math and insights issue that is alluded to as the Monty Hall issue. The diversion structure and the arrangement of the Monty Hall issue have been seriously talked about scholastically. This paper will show the long-run impacts of utilizing these two procedures. The quantum way helps to understand the solution of the Monty Hall problem. In particular, the quantum version is useful in establishing the concept of whether the contestant should stay with initial choice or switch to the other door.

\section{BACKGROUND}

The Monty Hall Problem has been settled and endorsed in various ways, including Bayes' Theorem [11] [12]. The Monty Hall issue has demonstrated in the written work of science and estimations for quite a while [1]. Perhaps the most recent trade and reasonable dialog concentrated on an everyday paper portion by Marilyn vos Savant, which discussed in September 1990. That request was: "Assume you are on a diversion show up, and you are given the choice of three entryways. Behind one entryway is an auto; behind the others are goats. You pick an entryway, say 1 and the host, who perceives what is behind the entryway, opens the rest of the entryway, say No. 3, which has a goat. He then says to you " Do you have to pick entryway No. 2?" Is it additionally supporting your favorable luck to switch your choice? "Craig F. Whitaker, Columbia, MD." Ms. vos Savant responded that there was the best reply. She communicated that one should constantly switch. She proceeded to state that by trading, one would have twofold the odds of winning the auto by transforming from the important decision. Her answer set off a tornado of verbal encounter and talk. Ms. vos Savant assessed that she got 10,000 letters and that most couldn't resist repudiating her. Most likely key messages started from mathematicians and specialists. Noted mathematician Andrew Vazsonyi has formed broadly concerning the three entryways issue. He even named his life account Which Door Has the Cadillac: Adventures of a Real-Life Mathematician. In an article circulated in Decision Line, Dr. Vazsonyi inspects his preoccupation and disillusionment at the feebleness of the people who should comprehend that Ms. vos Savant was an unmistakably idea in proposing that trading was the best procedure [2]. An particularly captivating exchange happened among Vazsonyi and its awesome friend Paul Erdos. Erdos was "one of the century's most unmistakable mathematicians, who acted and handled prickly issues in number speculation and diverse zones and built up the field of discrete numbercrunching, which is the foundation of programming designing. He was a champion among the most profitable mathematicians ever, with more than 1,000 papers to his name." [3] Vazsonyi relays how in 1995, in the wake of alluding the goats and Cadillac issue and the reply (trustworthy switch), Erdos responded "No. That is incomprehensible." Vazsonyi was induced, close by various others, that decision trees would give comprehension and help other individuals to see why the trading method was the correct answer. Pound built up the choice tree method in his paper "A Genuine Decision Tree for the Monty Hall Problem." [4] In both the 1999 paper and a resulting paper dispersed in 2003, Vazsonyi discussed the utilization of reenactment as a reply, furthermore the necessity for a "nonmathematical" illumination. Vos Savant also prescribed generation as a movement that would illuminate and persuade. There are different smart activities which have been created and are available on the web which reenacts the issue. Imagining propagation has furthermore been proposed. Diverse approaches to managing a classroom approach to managing to emulate the problem have been involved by Umble and Umble and Taras and Grossman. The way to the utilization of propagation of this issue is that the example size of the reenactment runs must be satisfactory. As will be represented, here and there innumerable are required before the aftereffect of the Law of Large Numbers can be viewed. Moreover, essential is a perception of the fundamentals of the preoccupation as described in advance. It is possible that a 
misguided judgment of one or a more noteworthy measure of the key standards could elucidate why such an assortment of individuals disregard to see why trading is reliably the better activity. Dr. Vazsonyi attempted to give a "non-numerical" plan in 2003. He perceived each imaginable come about for trading and counted the amounts of wins and adversities. His procedure is replicated in Table 1, with a few adjustments [5]. As appeared in Table 1, of the nine likely outcomes, by trading, one will win six circumstances. It is decisively 2 to 1 or a duplicating of the probability of winning, as suggested by vos Savant in her day by day paper area, and by Vazsonyi and various others, mathematicians and non-mathematicians alike.

\section{CLASSICAL MONTY HALL PROBLEM}

The guidelines of established Monty Hall Problem are the following:

1. The quantity of doors in the amusement is three. Toward the start of the amusement, a prize will be set behind every entryway. Behind one of the entryways is another auto. Others two entryways are goats.

2. The player will pick one of the doors.

3. The host of the amusement will open the way to furnish the player with a contrasting option to their decision.

4. After opening one entryway, the host inquires as to whether he might want to keep his underlying choice or change to the staying unopened entryway.

5. The player ought to settle on a specific choice to either stay or switch.

6. Should the player stay or change their unique decision?

\section{SIMULATION OF THE MONTY HALL PROBLEM}

The Simulation model is an instructing application that has been utilized to take care of and affirm the issue of Monty Hall by EXCEL. The answer plainly showed that the player ought to dependably trade his or her unique decision. Table 3 shows that this teaching application used the statistical average of 1000 times.

Table 3: The Average of Running 1000 times

\begin{tabular}{|l|l|l|}
\hline & Switch & No Switch \\
\hline Mean & 65 & 35 \\
\hline Median & 68 & 32 \\
\hline Mode & 66 & 33 \\
\hline Minimum & 54 & 18.5 \\
\hline Maximum & 80 & 46 \\
\hline
\end{tabular}

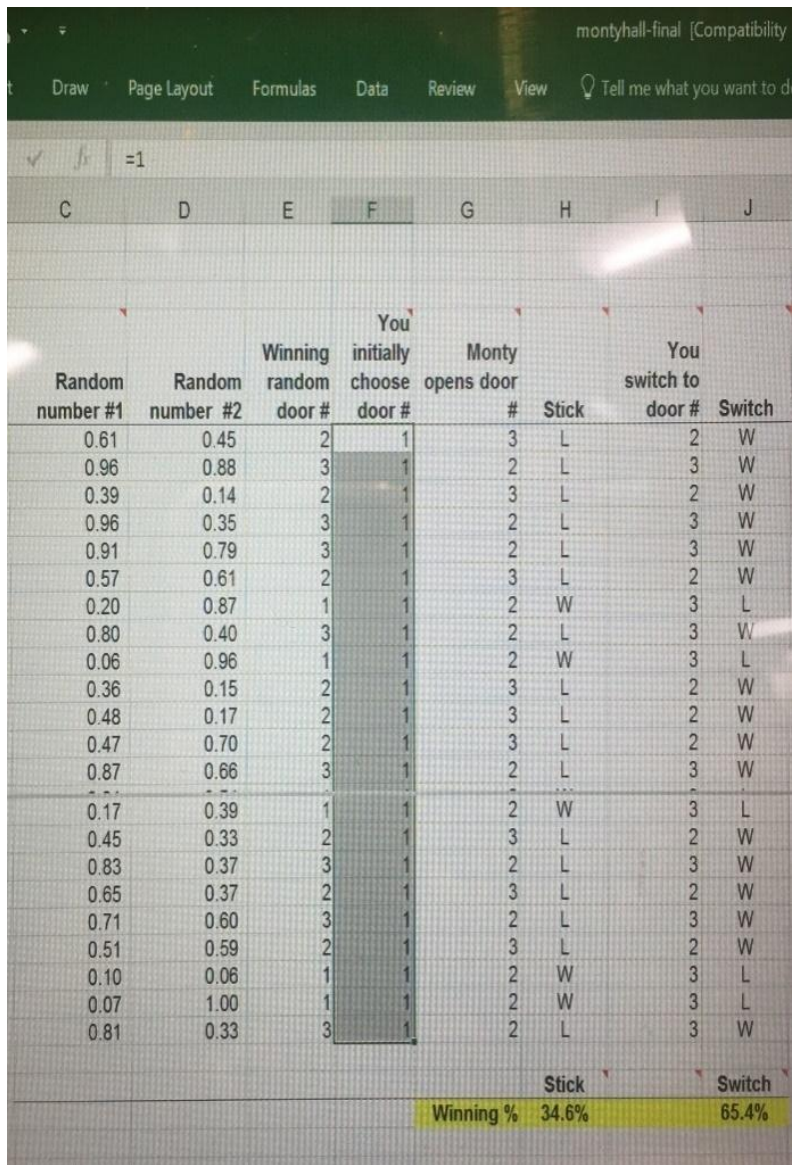

\section{MONTY HALL PROBLEM BY QUANTUM THEORY}

Quantum Theory is one of many ways to solve and approve the Monty Hall Problem. It is clear that Quantum Monty Hall Problem is a modern version for this problem, which is no articles talk about it. This section will take a glance how to solve the problem with the critical quantum theory. To describe the quantum version of the Monty Hall problem needs a quantum system with three energy states. The quantum way is being considered. The initial quantum system can be represented in the Dirac Notation.

First Energy State $\quad \mid 0>=\left(\begin{array}{l}1 \\ 0 \\ 0\end{array}\right)$

Second Energy State $\mid 1>=\left(\begin{array}{l}0 \\ 1 \\ 0\end{array}\right)$

Second Energy State $\mid 2>=\left(\begin{array}{l}0 \\ 0 \\ 1\end{array}\right)$

It is assumed that initially, these three energy states are in the superposition state. The quantum superposition state is defined as physical system there exists partially in all its particular theoretically chance states simultaneously; but when measured or observed. It gives a result corresponding to only one of the possible. The density matrix of the original superposition state can be represented as shown 
$P=\left(\begin{array}{ccc}\frac{1}{3} & 0 & 0 \\ 0 & \frac{1}{3} & 0 \\ 0 & 0 & \frac{1}{3}\end{array}\right)$

The corresponding position probabilities of the wave functions:

Probability of the First Energy

$<0|\rho| 0>=\left(\begin{array}{lll}1 & 0 & 0\end{array}\right)\left(\begin{array}{ccc}\frac{1}{3} & 0 & 0 \\ 0 & \frac{1}{3} & 0 \\ 0 & 0 & \frac{1}{3}\end{array}\right)\left(\begin{array}{l}1 \\ 0 \\ 0\end{array}\right)=\frac{1}{3}$

Probability of the Second Energy

$<1|\rho| 1>=\left(\begin{array}{lll}0 & 1 & 0\end{array}\right)\left(\begin{array}{ccc}\frac{1}{3} & 0 & 0 \\ 0 & \frac{1}{3} & 0 \\ 0 & 0 & \frac{1}{3}\end{array}\right)\left(\begin{array}{l}0 \\ 1 \\ 0\end{array}\right)=\frac{1}{3}$

Probability of the Third Energy

$<2|\rho| 2>=\left(\begin{array}{lll}0 & 0 & 1\end{array}\right)\left(\begin{array}{ccc}\frac{1}{3} & 0 & 0 \\ 0 & \frac{1}{3} & 0 \\ 0 & 0 & \frac{1}{3}\end{array}\right)\left(\begin{array}{l}0 \\ 0 \\ 1\end{array}\right)=\frac{1}{3}$

Table 2:The initial system for Monty Hall problem describes below

\begin{tabular}{|c|c|c|}
\hline $\begin{array}{c}\text { Quantum Number } \\
(\mathrm{n})\end{array}$ & $\begin{array}{c}\text { Energy } \\
\left(E_{n}\right)\end{array}$ & $\begin{array}{c}\text { Wave Functions } \\
\left(\Psi_{n}\right)\end{array}$ \\
\hline 0 & $\frac{1}{3}$ & $\mid 0>=\left(\begin{array}{l}1 \\
0 \\
0\end{array}\right)$ \\
\hline 1 & $\frac{1}{3}$ & $\mid 1>=\left(\begin{array}{l}0 \\
1 \\
0\end{array}\right)$ \\
\hline 2 & $\frac{1}{3}$ & $\mid 2>=\left(\begin{array}{l}0 \\
0 \\
1\end{array}\right)$ \\
\hline
\end{tabular}

The table 2 is for the initial system which means before a player begins a game. After the player manipulates with the Monty Hall problem, it is the density matrix will be changed to the new density matrix as shown

$P=\left(\begin{array}{ccc}\frac{1}{3} & 0 & 0 \\ 0 & \frac{1}{3} & \pm \frac{1}{3} \\ 0 & \pm \frac{1}{3} & \frac{1}{3}\end{array}\right)$

After determining the new density matrix, it will have

$\lambda=0, \lambda=1 / 3$ and $\lambda=2 / 3$

Where $\lambda$ is eigenvalues.

The corresponding eigenvectors are

$$
\begin{aligned}
& V_{\frac{1}{3}}=\frac{1}{\sqrt{2}}\left(\begin{array}{l}
0 \\
1 \\
1
\end{array}\right), V_{0}=\left(\begin{array}{l}
1 \\
0 \\
0
\end{array}\right), V_{\frac{2}{3}}=\frac{1}{\sqrt{2}}\left(\begin{array}{c}
0 \\
1 \\
-1
\end{array}\right) \\
& <0|\rho| 0>=\left(\begin{array}{lll}
1 & 0 & 0
\end{array}\right)\left(\begin{array}{ccc}
\frac{1}{3} & 0 & 0 \\
0 & \frac{1}{3} & -\frac{1}{3} \\
0 & -\frac{1}{3} & \frac{1}{3}
\end{array}\right)\left(\begin{array}{l}
1 \\
0 \\
0
\end{array}\right)=\frac{1}{3}
\end{aligned}
$$

$<1|\rho| 1\rangle=\left(\begin{array}{lll}0 & \frac{1}{\sqrt{2}} & \frac{1}{\sqrt{2}}\end{array}\right)\left(\begin{array}{ccc}\frac{1}{3} & 0 & 0 \\ 0 & \frac{1}{3} & -\frac{1}{3} \\ 0 & -\frac{1}{3} & \frac{1}{3}\end{array}\right)\left(\begin{array}{c}0 \\ \frac{1}{\sqrt{2}} \\ \frac{1}{\sqrt{2}}\end{array}\right)=0$

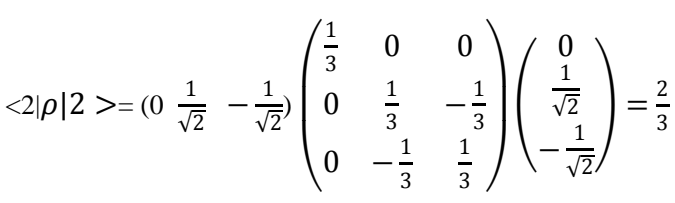

Table 3: The final system for MHP

\begin{tabular}{|c|c|c|}
\hline $\begin{array}{c}\text { Quantum } \\
\text { Number } \\
(\mathrm{n})\end{array}$ & $\left(E_{n}\right)$ & $\begin{array}{c}\text { Wave Functions } \\
\left(\Psi_{n}\right)\end{array}$ \\
\hline 0 & $\frac{1}{3}$ & $\mid \mathbf{0}>=\left(\begin{array}{c}\mathbf{1} \\
\mathbf{0} \\
\mathbf{0}\end{array}\right)$ \\
\hline 1 & 0 & $\frac{|\mathbf{1}>-| 2\rangle}{\sqrt{2}}=\left(\begin{array}{c}\mathbf{1} \\
\sqrt{2} \\
\frac{\mathbf{1}}{\sqrt{2}}\end{array}\right)$ \\
\hline 2 & $\frac{2}{3}$ & $\frac{\mid \mathbf{1 > + | 2 >}}{\sqrt{2}}$ \\
& & $\left(\begin{array}{c}\mathbf{0} \\
\frac{\mathbf{1}}{\sqrt{2}} \\
-\frac{\mathbf{1}}{\sqrt{2}}\end{array}\right)$ \\
\hline
\end{tabular}

\section{FUTURE WORK}

There are many paradoxes and the unsolved problem associated with quantum information, and the study of quantum game theory is a useful tool to explore this area.

\section{CONCLUSION}

The quantum show showed in this paper is proposed to offer learning to the considerable Monty Hall issue and give a choice approach to manage use in training the related probability measures. Different techniques have been utilized to elucidate why trading an entryway will build the odds of winning in the wake of seeing an entryway, not the one with the auto and not the one at first picked by the hopeful. For a couple, the probability or decision tree is the favored instrument for examination. Others have utilized imagining as a part of a classroom space. The trade and open contention made by the irrational right plan continues up 'til the present time. It is noteworthy that no short of what one master mathematician who at initially ambushed Ms. vos Savant had the dauntlessness to yield his error. Robert Sachs of George Mason University had initially tried vos Savant and said that 
she was off course by making her, "I'm incredibly stressed over the general populace's nonappearance of logical capacities. It will be perfect in the event that you help by conceding your mistake." After understanding that vos Savant was, indeed, right, and he wasn't right, he talked with her. "I thought about her another letter informing her that in the wake concerning ousting my foot from my mouth, I'm quickly attempting to back-hawk. I guaranteed as a compensation to answer each one of the overall public who created to censure me. It's been an uncommon master humiliation. Maybe a misguided judgment of the suppositions and standards, as of now discussed, is a fragmented illumination of the disappointment of individuals to understand the issue. Possibly it is that the correct answer is irrational. As vos Savant communicated, "When reality clashes so violently with impulse people are shaken" Such is frequently the case with business estimations understudies, especially the people who rely on upon unique courses of action and plans for issue including probabilities (e.g. are these events free?). Choosing the probability of duplicate birthdays in a classroom of understudies, an every now and again used classroom showing tends to be unreasonable [6]. It is the trust of the scholars that the spreadsheet amusement demonstrate system laid out in this paper will give a choice approach to manage both teaching and understanding the huge probability issue known as the Monty Hall issue.

\section{ACKNOWLEDGEMENTS}

The author would like to thank my supervisor, DR. X.Q. Wang, for his preparing me during the processes of the research. Saudi Arabian Cultural Missio funds research of Mazen Alrahili through Taibah University.

Table 1: Monty Hall Problem (not- Switching) stay Strategy

\begin{tabular}{|c|c|c|c|c|c|}
\hline Number & $\begin{array}{l}\text { Prize } \\
\text { Behind }\end{array}$ & $\begin{array}{l}\text { You } \\
\text { choose }\end{array}$ & $\begin{array}{l}\text { Monty } \\
\text { Opens }\end{array}$ & Stay & Results \\
\hline 1 & 1 & 1 & 2 or 3 & 1 & Win \\
\hline 2 & 1 & 2 & 3 & 2 & Lose \\
\hline 3 & 1 & 3 & 2 & 3 & Lose \\
\hline 4 & 2 & 1 & 3 & 1 & Lose \\
\hline 5 & 2 & 2 & 1 or 3 & 2 & Win \\
\hline 6 & 2 & 3 & 1 & 3 & Lose \\
\hline 7 & 3 & 1 & 2 & 1 & Lose \\
\hline 8 & 3 & 2 & 1 & 2 & Lose \\
\hline 9 & 3 & 3 & 1 or 2 & 3 & Win \\
\hline
\end{tabular}

Table 2: Monty Hall Problem swapping Strategy.

\begin{tabular}{|c|c|c|c|c|c|}
\hline $\begin{array}{l}\text { Case } \\
\text { Number }\end{array}$ & $\begin{array}{l}\text { Car } \\
\text { Behind }\end{array}$ & $\begin{array}{l}\text { You } \\
\text { Guess }\end{array}$ & $\begin{array}{l}\text { Monty } \\
\text { Opens }\end{array}$ & $\begin{array}{l}\text { Switch } \\
\text { to }\end{array}$ & Results \\
\hline 1 & 1 & 1 & 2 or 3 & 3 or 2 & Lose \\
\hline 2 & 1 & 2 & 3 & 1 & Win \\
\hline 3 & 1 & 3 & 2 & 1 & Win \\
\hline 4 & 2 & 1 & 3 & 2 & Win \\
\hline 5 & 2 & 2 & 1 or 3 & 3 or 1 & Lose \\
\hline 6 & 2 & 3 & 1 & 2 & Win \\
\hline 7 & 3 & 1 & 2 & 3 & Win \\
\hline 8 & 3 & 2 & 1 & 3 & Win \\
\hline 9 & 3 & 3 & 1 or 2 & 2 or 1 & Lose \\
\hline
\end{tabular}




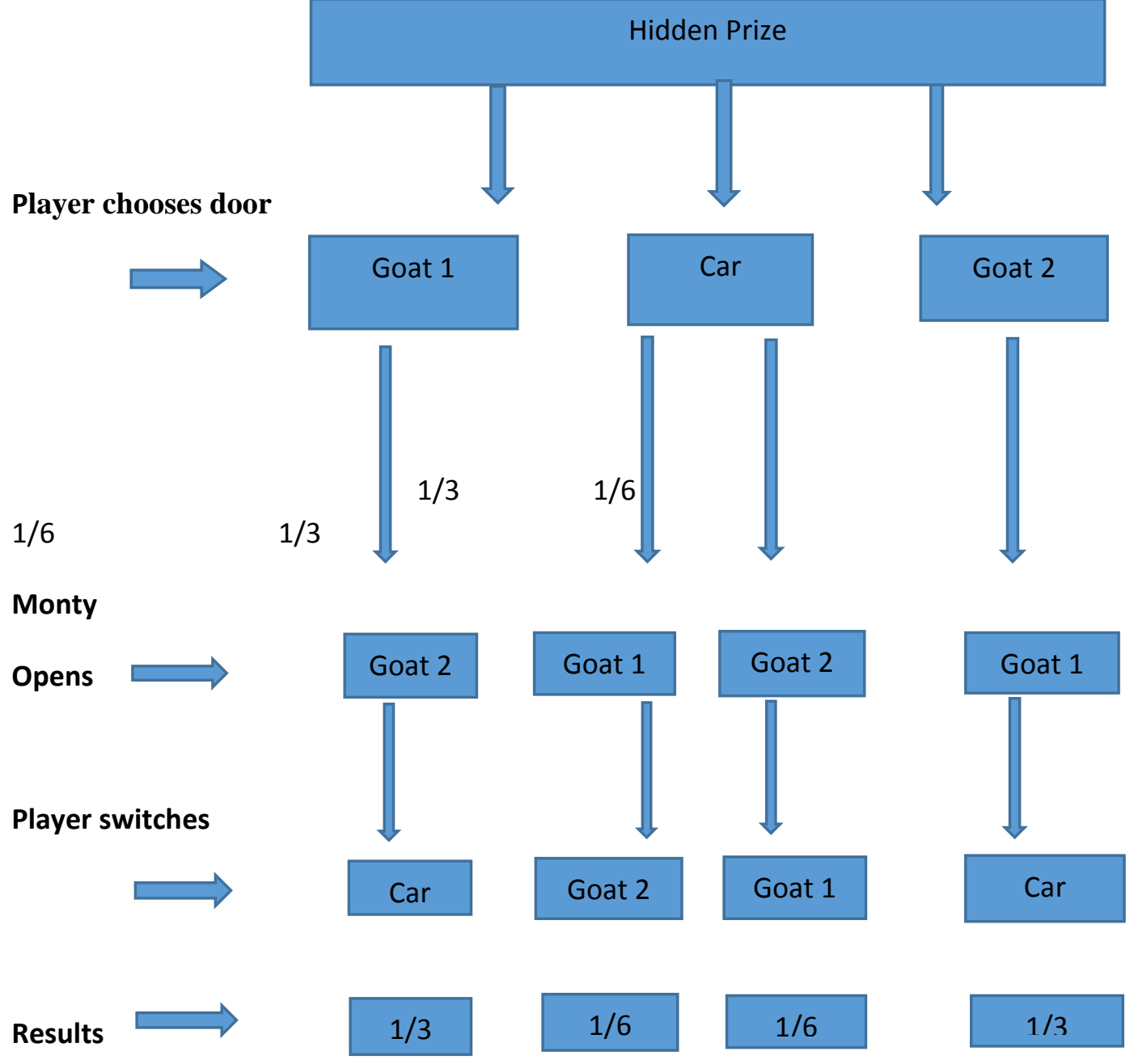

Final Results of Swapping

$$
\begin{aligned}
& (1 / 3)+(1 / 3)=2 / 3 \text { of winning a car } \\
& (1 / 6)+(1 / 6)=1 / 3 \text { of winning a car }
\end{aligned}
$$

Figure 1: Traditional Model of MHP. 


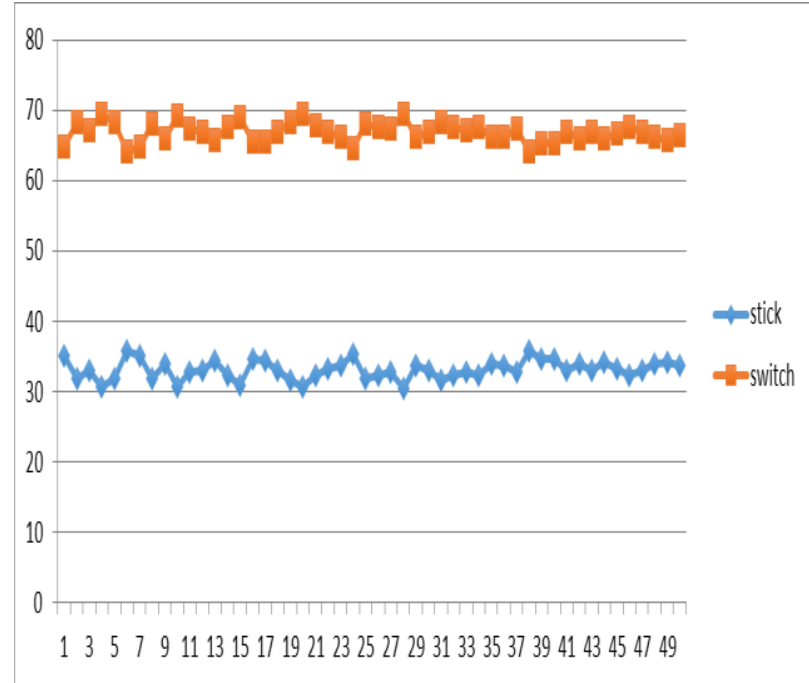

Figure 2: The percentage between sticking and switching

\section{REFERENCES}

[1] Bowman, M., Debray, S. K., and Peterson, L. L. 1993. Reasoning about naming systems.

[2] Ding, W., and Marchionini, G. 1997 A Study on Video Browsing Strategies. Technical Report. The University of Maryland at College Park.

[3] Fröhlich, B., and Plate, J. 2000. The cubic mouse: a new device for three-dimensional input. In Proceedings of the
SIGCHI Conference on Human Factors in Computing Systems

[4] Tavel, P. 2007 Modeling, and Simulation Design. AK Peters Ltd.

[5] Sannella, M. J. 1994 Constraint Satisfaction and Debugging for Interactive User Interfaces. Doctoral Thesis. UMI Order Number: UMI Order No. GAX9509398., The University of Washington.

[6] Forman, G. 2003. An extensive empirical study of feature selection metrics for text classification. J. Mach. Learn. Res. 3 (Mar. 2003), 1289-1305.

[7] Brown, L. D., Hua, H., and Gao, C. 2003. A widget framework for augmented interaction in SCAPE.

[8] Y.T. Yu, M.F. Lau, "A comparison of MC/DC, MUMCUT and several other coverage criteria for logical decisions," Journal of Systems and Software, 2005, in press.

[9] Spector, A. Z. 1989. Achieving application requirements. In Distributed Systems, S. Mullender.

[10] Rosenhouse, J. (2009) The Monty Hall Problem. Oxford University Press, New York.

[11] Mazen Alrahili. Simulation of the Monty Hall Problem. International Journal of Computer Applications 152(6):16-19, October 2016. 